\title{
Production Efficiency of Capsicum under Protected Cultivation in North West Region of Tamil Nadu, India
}

\author{
S. Senthilkumar ${ }^{1 *}$, K. R. Ashok ${ }^{2}$, M. Chinnadurai ${ }^{3}$ and K. Sathyamoorthi ${ }^{4}$
}

\author{
${ }^{1}$ Department of Agricultural Economics, CARDS, TNAU, Coimbatore, Tamil Nadu, India \\ ${ }^{2}$ Department of Agricultural and Rural Management, TNAU, Coimbatore, Tamil Nadu, India \\ ${ }^{3}$ Directorate of Centre for Agricultural and Rural Development Studies, TNAU, Coimbatore, \\ Tamil Nadu, India \\ ${ }^{4}$ Directorate of Research, TNAU, Coimbatore, Tamil Nadu, India
}

*Corresponding author

\begin{tabular}{|l|}
\hline Ke y w o r d s \\
$\begin{array}{l}\text { Protected cultivation, } \\
\text { Resource use efficiency, } \\
\text { Technical efficiency, } \\
\text { Capsicum production }\end{array}$ \\
\hline Article Info \\
\hline $\begin{array}{l}\text { Accepted: } \\
\text { 20 May 2018 } \\
\text { Available Online: } \\
\text { 10 June 2018 }\end{array}$ \\
\hline
\end{tabular}

A B S T R A C T

Polyhouse farming is one among the major modifications in advanced farming techniques that are manifestation of plastic-culture. Protected cultivation or greenhouse cultivation would be the most contemporary approach. In India, the total production of capsicum was 327 thousand tons from an area of 46 thousand hectare with the productivity of $7108 \mathrm{~kg}$ per hectare. However, it was relatively low when compare to world productivity. Against this back ground, the present study addressed to estimate the resource use efficiency and technical efficiency of the farms that cultivate capsicum crops under protected cultivation. Resource use efficiency of capsicum cultivation, the co-efficient of multiple determinations $\left(\mathrm{R}^{2}\right)$ was 0.86 . It implies 86 per cent of the variation in the dependent variable was accounted by the selected independent variables. Quantity of seedlings and human labour were significant at one per cent level would imply that an increase in seedling rate and human labour by one per cent from their respective mean levels, ceteris paribus, would increase the yield by 0.18 per cent and 0.23 per cent respectively. Stochastic frontier production function analysis results of capsicum cultivation, the coefficient of expenditure on plant protection chemicals was significant at one per cent with the value 0.1726 and also quantity of seedlings, expenditure on fertilizer and human labour significance at five per cent level with the coefficient value $0.1089,0.1086$ and 0.1379 , which implied that one per cent, increase in the respective inputs could increase the capsicum yield. The average technical efficiency of sampled capsicum farms under protected cultivation was around 83.64 per cent. The farmers can optimize the production frontier of the capsicum cropping system by overcoming the existing level of technical inefficiencies.

\section{Introduction}

Developing world agriculture had been benefiting from major technological gains originating from the green revolution.
Productivity gains from a use of existing technology. The major prerequisites of farm production are a modification from conventional farming to modern farming. Modern agriculture is a combination of 
technical change and advancement in production inputs. Farm average production can be increased considerably through modern farming techniques (Hina et al., 2017). Polyhouse farming is one among the major modifications in advanced farming techniques that are manifestation of plastic-culture. The plastic-culture is known as usage of plastic material in the farm sector. Protected or greenhouse cultivation of high value vegetables and cut-flowers has shown tremendous potential for farmer's wellbeing's. The technologies creating avenues at higher level and also to the growers with the smaller landholdings as the higher productivity levels retain economic relevance to agriculture. Protected cultivation is precise, progressive and parallel agriculture encompassing virtually all facets of agriculture rather scrutiny of technical relevance to situations and grower and market economics. Since protected cultivation is a vast assembly of diverse aspects of agriculture.

The development of worldwide protected cultivation to produce horticultural products with relatively safe and health products for human life has increased due to the increase of demand for fruits/vegetables (as increasing world population), and rising standard of living. This technology was also one of the promised technologies adopted that influence in increasing income of the farmer and overcome the limitation on agricultural land for horticultural product.

Protected cultivation in the field of horticulture is likely to play an important role to increase production (quantity and quality) to meet ever increasing food and nutritional requirements. In the past, unfavourable conditions led to the development of protected structures. Later, natural conditions were modified and control devices evolved according the need of the crop to harness the increased quality yield. Under present situation the demand for fruits, vegetables and other crops is rising, quality parameters are changing with noticeable shift in the nature of climate. Greenhouse technology has potential to increase the efficiency of input needed for crop production. It may be used to surmount disadvantages in the growing qualities of a piece of land e.g. limited growing season or inadequate light levels or marginal environments. In addition, greenhouse technology can also be used to raise healthy seedlings early in the seasons also off -season making cultivation more profitable.

National Horticulture Mission (NHM), Ministry of Agriculture, Government of India, deems greenhouse technology potential in producing high quality of a range of horticultural products to raise the farmer's income and improve their availability for extended period. NHM, through various schemes, extend support growing and processing of horticultural crops (fruits, vegetables, ornamental, plantation crops, spices etc.) in the country. It provides subsidy from 35 to 50 per cent of project cost of protected cultivation.

In India, the total production of capsicum was 327 thousand tons from an area of 46,000 hectare with the productivity of $7108.70 \mathrm{~kg}$ per hectare. Capsicum is extensively cultivated in Karnataka, Madhya Pradesh, Andhra Pradesh, Maharashtra, Tamil Nadu, Himachal Pradesh, and hilly areas of Uttar Pradesh.

Among the states, Karnataka stands first with the area of 4130 ha and production of 81.67 thousand tons followed by Himachal Pradesh with the area of 2500 ha and production of about 58.29 thousand tons. Capsicum is extensively cultivated in north western region and hilly region of Tamil Nadu produce of 600 tons with the area of 90 ha (Horticultural statistics at a glance 2017). 
Technological adoption in agricultural sector is now moving in a positive direction. Technological adoption most probably sustenance in intensify the production, efficiency and cost effectiveness of agricultural sector. However, the role of hightech farming may reduce without the positive contribution in farmer's education, technical skills, and managerial abilities. Farmer's ability to take decision regarding input utilization plays a crucial role towards high levels of farm productivity and efficiency. Improved farm management practices may enhance the returns of technological adoption manifolds. The objective of the study is to estimate the resource use efficiency and technical efficiency of the farms that cultivate capsicum crops under protected cultivation.

\section{Materials and Methods}

In Tamil Nadu, Krishnagiri district was purposively selected for the study in the first stage, since; it occupied the first position in area under protected cultivation of horticultural crops in the state of Tamil Nadu. Area under protected cultivation were 5,38,503 square meters, and it contributes 63 per cent in the state of Tamil Nadu for the period of 2015-16. In the second stage, among the blocks in Krishnagiri district, based on area under cut flowers and capsicum Soolagiri, Thally, Hosur and kelamangalam blocks were selected purposively.

In the third stage of sampling, Beneficiaries records of availed 50 per cent subsidy from National Horticulture Mission (NHM) of the selected blocks were obtained from the office of Deputy Director of Horticulture, State Department of Horticulture, Krishnagiri. Thereafter, 120 farmers were selected randomly within the four blocks of Krishnagiri district. In Capsicum cultivation under protected cultivation of 30 sample farmers selected for the present study. The present study based on primary data, collected through detailed interviews based on a questionnaire. Production function analysis was used to evaluate the factors influencing the capsicum cultivation and also to examine their relative efficiencies. Efficiency of resources used in production could be known only if the technical relationships between outputs and inputs are estimated.

\section{Cobb-Douglas production function}

The production functions were estimated using Ordinary Least Square (OLS) method. The estimated values of the regression coefficient and $\mathrm{R}^{2}$ were tested for statistical significance. The Cobb-Douglas production function of the following form was finally specified based on the a priori expectations.

The form of regression model used was

$\mathrm{Y}=\mathrm{a} \mathrm{X}_{1}^{\mathrm{b} 1} \mathrm{X}_{2}^{\mathrm{b} 2} \mathrm{X}_{3}{ }^{\mathrm{b} 3} \mathrm{X}_{4}^{\mathrm{b} 4} \mathrm{X}_{5}^{\mathrm{b} 5} \mathrm{X}_{6}{ }^{\mathrm{b} 6} \mathrm{X}_{7}^{\mathrm{b} 7} \mathrm{U}_{\mathrm{t}}$

Where,

$\mathrm{Y}=$ Yield of $\mathrm{i}^{\text {th }}$ crop (bunches $/ \mathrm{kgs} / 4000 \mathrm{~m}^{2}$ )

$\mathrm{X}_{1}=$ Size of the poly house $\left(\mathrm{m}^{2}\right)$

$\mathrm{X}_{2}=$ Quantity of Seed rate (seedlings/corms/rooted cuttings/4000 $\mathrm{m}^{2}$ )

$\mathrm{X}_{3}=$ Quantity of farmyard manure (tonnes $/ 4000 \mathrm{~m}^{2}$ )

$\mathrm{X}_{4}=$ Expenditure on fertilzer $\left(\mathrm{Rs} / 4000 \mathrm{~m}^{2}\right)$

$\mathrm{X}_{5}=$ Expenditure on plant protection chemicals $\left(\mathrm{Rs} / 4000 \mathrm{~m}^{2}\right)$

$\mathrm{X}_{6}=$ Human labour $\left(\right.$ Man days $\left./ 4000 \mathrm{~m}^{2}\right)$

$\mathrm{X}_{7}=$ Machine labour $\left(\mathrm{Hrs} / 4000 \mathrm{~m}^{2}\right)$

$\mathrm{a}=$ Intercept/Constant term 
$\mathrm{b}_{1}-\mathrm{b}_{7}=$ Regression coefficients/ Elasticities of Production

$\mathrm{u}$ is error term.

\section{Stochastic Frontier Production Function}

The concept of efficiency, introduced by Farrell (1957), is based on the identical deterministic production function which assumes that all the deviation from production frontier is due to variations in efficiency. The estimation process of production frontier, this concept ignores the impact of uncontrollable exogenous variables, such as natural adversities, weather conditions and measurement. Stochastic production frontier is a useful method of finding out the efficient use of resources on the farm. Aigner, et al., (1977), Battese and Coelli (1993) broadening the stochastic production approach have used it to calculate efficiency of farmers in resource use. The frontier analysis incorporates the issues of inefficiency in production function and assumes that farms are not always on the 'best practice' production level.

Stochastic frontier production function was attempted to measure the technical efficiency in the capsicum production. Maximum Likelihood Estimation (MLE) procedure was adopted for the estimation of the parameters involved. The procedure for stochastic frontier production function is discussed below.

The stochastic frontier production function with a composed error term is more suitable to estimate the technical efficiency. The general form of the stochastic frontier production function is:

$Y_{i}=X_{i} \alpha+v_{i}-u_{i}(1)$

Where,

$\mathrm{Y}_{\mathrm{i}}$ is the dependent variable,
$X_{i}$ are the independent variables and $\alpha$ is the regression coefficient.

In this model the dependent variable is bounded by the stochastic variable $v_{i}-u_{i}$. The random error, $\mathrm{v}_{\mathrm{i}}$ can be positive or negative. It captures the effects of random shocks outside the farmer's control, observation and measurement error on dependent variable and statistical noise. The other independent error term $u_{i}$ is a non- negative term representing farm specific technical inefficiency in the sense that it measures short fall in output $\left(\mathrm{Y}_{\mathrm{i}}\right)$ from its maximum possible value given by stochastic frontier.

When the model (1) is estimated, one can measure the mean technical efficiency of a farm. The following functional form was used to estimate the individual technical efficiencies and to examine the factors affecting them. The analysis is done (1) in a single step procedure by combining the following models (2) and (3) using a computer program FRONTIER version 4.1.

$\operatorname{Ln}(\mathrm{Yi})=\alpha 0+\sum_{k=1}^{n} \alpha \mathrm{k} \operatorname{Ln}(\mathrm{Xki})+\mathrm{vi}-\mathrm{ui}$

$\mathrm{ui}=80+\sum_{k=1}^{n} \delta \mathrm{m} . \mathrm{Zm}$

Where,

$Y_{i}=$ output of $i^{\text {th }}$ crop (bunches $/ \mathrm{kgs} / 4000 \mathrm{~m}^{2}$ )

$\mathrm{X}_{\mathrm{ki}}=$ use of $\mathrm{k}^{\text {th }}$ input

$\mathrm{v}_{\mathrm{i}}=$ random error to be identically and independently distributed $\mathrm{N}\left(0, \sigma^{2} \mathrm{~V}\right)$

$\mathrm{u}_{\mathrm{i}}=$ farm specific inefficiency effect

$\mathrm{Z}_{\mathrm{m}}=$ factors affecting technical inefficiency.

$\alpha$ 's and $\delta$ 's $=$ regression coefficients to be estimated. 
The stochastic frontier production function model specified for cut flowers were given below.

$\operatorname{Ln}(\mathrm{Y})=\alpha_{0}+\alpha_{1} \ln \left(\mathrm{X}_{1}\right)+\alpha_{2} \ln \left(\mathrm{X}_{2}\right)+\alpha_{3} \ln \left(\mathrm{X}_{3}\right)$ $+\alpha_{4} \ln \left(\mathrm{X}_{4}\right)+\alpha_{5} \ln \left(\mathrm{X}_{5}\right)+\alpha_{6} \ln \left(\mathrm{X}_{6}\right)+\alpha_{7} \ln \left(\mathrm{X}_{7}\right)+$ $\mathrm{v}_{\mathrm{i}}-\mathrm{u}_{\mathrm{i}}$

$\mu=\delta_{0}+\delta_{1} z_{1}+\delta_{2} z_{2}+\delta_{3} z_{3}$

Where,

$\mathrm{Y}=$ Yield of $\mathrm{i}^{\text {th }}$ crop (bunches/kgs/4000 $\mathrm{m}^{2}$ )

$X_{1}=$ Size of the poly house $\left(\mathrm{m}^{2}\right)$

$\mathrm{X}_{2}=$ Quantity of Seed rate (seedlings/corms/rooted cuttings/4000 $\mathrm{m}^{2}$ )

$\mathrm{X}_{3}=$ Quantity of farmyard manure (tonnes/4000 $\mathrm{m}^{2}$ )

$\mathrm{X}_{4}=$ Expenditure on fertilzer $\left(\mathrm{Rs} / 4000 \mathrm{~m}^{2}\right)$

$\mathrm{X}_{5}=$ Expenditure on plant protection chemicals (Rs/4000 $\mathrm{m}^{2}$ )

$\mathrm{X}_{6}=$ Human labour (man days $/ 4000 \mathrm{~m}^{2}$ )

$\mathrm{X}_{7}=$ Machine labour $\left(\mathrm{Hrs} / 4000 \mathrm{~m}^{2}\right)$

$\mathrm{a}=$ Intercept/Constant term

$\mathrm{Z}_{1}=$ Experience in flowers farming (in years)

$\mathrm{Z}_{2}=$ Education of the farmer (in years)

$\mathrm{Z}_{3}=$ Family size (in numbers)

\section{Results and Discussion}

\section{Production function analysis of capsicum under protected cultivation}

The result of the study indicates that factors are influencing capsicum cultivation and also examined their relative influence, production function was fitted. The Cobb-Douglas production function was used and the production elasticity's were estimated accordingly. The estimated values of the regression coefficients were tested for statistical significance with the help of ' $t$ ' test and the significance of the equation was tested by ' $F$ ' test for $R^{2}$. the yield of capsicum under protected cultivation was taken as dependent variable while size of the poly house $\left(\mathrm{M}^{2}\right)$, quantity of seedlings (Nos), quantity of farmyard manure (Tons), expenditure made on fertilizers (Rs), plant protection chemicals (Rs), Human labour (man days) and machine labour (Hrs) were taken as independent variables.

It could be seen from the Table 1 resource use efficiency of capsicum cultivation, the coefficient of multiple determinations $\left(\mathrm{R}^{2}\right)$ was 0.86 . This would show that about 86 per cent of the variation in the dependent variable was accounted by the selected independent variables. Quantity of seedlings and human labour were significant at one per cent level. This would imply that an increase in seedling rate (16228.83 plants) and human labour (1421.81 man days) by one per cent from their respective mean levels, ceteris paribus, would increase the yield by 0.18 per cent and 0.23 per cent respectively. It was also found that the quantity of farmyard manure and expenditure on plant protection chemicals were significant at five per cent level of mean, i.e., by increasing the quantity of farmyard manure (8.14 tons) and expenditure on plant protection chemicals (Rs. 23,186.54) by one per cent, the yield will increase by 0.09 per cent and 0.08 per cent respectively. The sum of the elasticity of regression co-efficient worked out to be 0.79, which implied decreasing returns to scale for capsicum cultivation. This implied that one per cent increase in all inputs for capsicum under protected cultivation from their respective geometric mean levels would reduce the yield by 0.79 per cent. 
Table.1 Resource use efficiency in capsicum cultivation: Cobb-Douglas Production function analysis

\begin{tabular}{|c|c|c|c|c|}
\hline $\begin{array}{l}\text { Sl. } \\
\text { No }\end{array}$ & Explanatory variables & Coefficient & $\begin{array}{l}\text { Std. } \\
\text { error }\end{array}$ & t-value \\
\hline 1. & Constant & $5.3436 * * *$ & 0.4339 & 12.3152 \\
\hline 2. & Size of the poly house $\left(\mathrm{M}^{2}\right)$ & -0.0011 & 0.0084 & -0.1309 \\
\hline 3. & Quantity of seedlings (seedlings/4000 $\mathrm{M}^{2}$ ) & $0.1677 * * *$ & 0.0558 & 3.0053 \\
\hline 4. & Quantity of farmyard manure (tons/ $4000 \mathrm{M}^{2}$ ) & $0.0909 * *$ & 0.0468 & 1.9423 \\
\hline 5. & Expenditure on fertilizer (Rs/4000 M²) & 0.0668 & 0.0628 & 1.0636 \\
\hline 6. & $\begin{array}{l}\text { Expenditure on plant protection chemicals } \\
\left(\mathrm{Rs} / 4000 \mathrm{M}^{2}\right)\end{array}$ & $0.0794 * *$ & 0.0334 & 2.3772 \\
\hline 7. & Human Labour (man days $/ 4000 \mathrm{M}^{2}$ ) & $0.2294 * * *$ & 0.0448 & 5.1205 \\
\hline \multirow[t]{4}{*}{8.} & Machine Labour (Hrs/4000 $\left.\mathrm{M}^{2}\right)$ & 0.0206 & 0.0286 & 0.7203 \\
\hline & R Square & 0.86 & & \\
\hline & Adjusted R Square & 0.78 & & \\
\hline & F Value & $113.78 * * *$ & & \\
\hline
\end{tabular}

(*** Significant at $1 \%$ level, $* *$ Significant at $5 \%$ level, $*$ Significant at $10 \%$ level)

Table.2 Stochastic frontier production function for capsicum cultivation

\begin{tabular}{|c|c|c|c|c|}
\hline $\begin{array}{l}\text { SI. } \\
\text { No }\end{array}$ & Variables & Coefficient & $\begin{array}{c}\text { Standard } \\
\text { error }\end{array}$ & t-ratio \\
\hline $\mathbf{A}$ & Frontier production function & & & \\
\hline 1 & Constant & $2.7253 * * *$ & 0.9549 & 2.8540 \\
\hline 2 & Size of the poly house $\left(\mathrm{M}^{2}\right)$ & 0.0721 & 0.1086 & 0.6639 \\
\hline 3 & Quantity of seedlings (seedlings/4000 $\mathrm{M}^{2}$ ) & $0.1089 * *$ & 0.0558 & 1.9516 \\
\hline 4 & Quantity of farmyard manure (tons/ $4000 \mathrm{M}^{2}$ ) & 0.0224 & 0.0149 & 1.5034 \\
\hline 5 & Expenditure on fertilizer $\left(\mathrm{Rs} / 4000 \mathrm{M}^{2}\right)$ & $0.1086^{* *}$ & 0.0564 & 1.9255 \\
\hline 6 & $\begin{array}{l}\text { Expenditure on plant protection chemicals } \\
\left(\mathrm{Rs} / 4000 \mathrm{M}^{2}\right)\end{array}$ & $0.1726 * * *$ & 0.0598 & 2.8863 \\
\hline 7 & Human Labour (man days $/ 4000 \mathrm{M}^{2}$ ) & $0.1379 * *$ & 0.0710 & 1.9423 \\
\hline 8 & Machine Labour (Hrs/4000 M²) & 0.1782 & 0.0962 & 1.8524 \\
\hline $\mathbf{B}$ & Technical inefficiency effects & & & \\
\hline$\overline{1}$ & Constant & $0.1782 * *$ & 0.0795 & 2.2415 \\
\hline 2 & Family Size (Nos) & -0.0032 & 0.0076 & 0.4211 \\
\hline $\mathbf{3}$ & Education (years) & -0.0015 & 0.0032 & 0.4688 \\
\hline 4 & Farming experience (years) & $0.0058 * * *$ & 0.0023 & 2.5218 \\
\hline \multirow[t]{5}{*}{$\mathbf{C}$} & Diagnosis Statistics & & & \\
\hline & Sigma-square $\left(\sigma^{2}\right)$ & $0.0045^{* * *}$ & 0.0018 & 2.5000 \\
\hline & Gamma $(\gamma)$ & $0.9999 * * *$ & 0.3428 & 2.9169 \\
\hline & Log- likelihood & 82.86 & & \\
\hline & Mean technical efficiency (\%) & 83.64 & & \\
\hline
\end{tabular}


Technical efficiency of capsicum cultivation under protected cultivation

A computer program FRONTIER version 4.1 developed by Tim Coelli, Centre for efficiency and productivity Analysis, University of New England, Austria, was used for the estimation of Stochastic Frontier Production function. The estimated stochastic frontier production function analysis for cut flowers and capsicum by using maximum likelihood method is furnished in Table 2.

The estimate of gamma $(\gamma)$ which is the ratio of the variance of farm specific performance of technical efficiency to total variance of output was significant at one per cent level, with a value of 0.99 , indicating the presence of one sided error component. This implied that the effect of technical inefficiency was significant. Hence the average production function (OLS) was not an adequate representation of the data. The variance ratio, defined by $\gamma=\sigma^{2} /\left(\sigma^{2} u+\sigma^{2} v\right)$, was estimated as 0.99 , implying that about 99.00 percent of the disparities between the observed output and the frontier output were due to technical inefficiency. In other words, the shortfall in observed output from the frontier output (one percent) was primarily due to the factors, which were within the control of the capsicum growers in the sample under study.

From the Table 2 Maximum likelihood estimation results of capsicum cultivation, the coefficient of expenditure on plant protection chemicals was significant at one per cent with the value 0.1726 , which implied that one per cent increase in the expenditure on plant protection chemicals could increase capsicum yield by 0.1379 percent and also quantity of seedlings, expenditure on fertilizer and human labour significance at five per cent level with the coefficient value $0.1089,0.1086$ and 0.1379 , which implied that one per cent, increase in the respective inputs could increase the capsicum yield by 0.1089 per cent, 0.1086 per cent and 0.1379 per cent respectively. Size of polyhouse and quantity of farmyard manure were not significant under capsicum cultivation. The inefficiency variable namely farming experience (years) was significant at one per cent. Family size and farming experience were non-significant. The mean technical efficiency was estimated at 83.64 per cent indicating that output can be raised by 16.36 per cent through following efficient crop management practices without actually increasing the level of application of inputs.

Polyhouse farming is one of the major modifications in advanced farming techniques that are manifestation of plastic-culture. Protected cultivation or greenhouse cultivation is the most contemporary approach. Cultivation of high value crops is yielding more rather than in the conventional farming system. Vegetable like capsicum yield few fold under protected cultivation. Resource use efficiency of capsicum cultivation, the co-efficient of multiple determinations $\left(\mathrm{R}^{2}\right)$ was 0.86 . It implies 86 per cent of the variation in the dependent variable was accounted by the selected independent variables. Quantity of seedlings and human labour were significant at one per cent level would imply that an increase in seedling rate and human labour. Stochastic frontier production function analysis results of capsicum cultivation, the coefficient of expenditure on plant protection chemicals was significant at one per cent with the value 0.1726 and also quantity of seedlings, expenditure on fertilizer and human labour significance at five per cent level with the coefficient value $0.1089,0.1086$ and 0.1379 , which implied that one per cent, increase in the respective inputs could increase the capsicum yield. The average technical efficiency of sampled capsicum farms under protected cultivation was around 83.64 per 
cent. The farmers can optimize the production frontier of the capsicum cropping system by overcoming the existing level of technical inefficiencies.

\section{References}

Aigner, D., Lovell, C.K. and Schmidt, P.J., (1977) "Formulation and estimation of stochastic frontier production function models", J. Econ., Vol. 6 (1): 21-37.

Ali Qamar, Ashfaq Muhammad, and Khan M. T. I., (2016) "An Economic analysis of Off-season Capsicum/Bell pepper Production in Punjab Pakisthan". ARPN Journal of Agricultural and Biological Science, Vol. 11(11) 424-430.

Battese, G. E. and Coelli, T.J., (1993) "A stochastic frontier production function incorporating a model for technical inefficiency effects", Working Papers in Econometrics and Applied Statistics No 69, Department of Econometrics. University of New England. Armidale.

Bhende, M. J. and Kalirajan, K. P., (2007) "Technical efficiency of major food and cash crops in Karnataka (India)", Indian Journal of Agricultural Economics, 62 (2): 176-190.

Coelli, T. J., (1995) "Recent developments in frontier modelling and efficiency measurement", Aus J of Agric Econ., Vol. (39): 219-246.

Farrell, M. J., (1957) "The measurement of production efficiency", J.R. Statis. Soc. Vol. (120): 257-281.
Hina Fatima, Lal Almas and Bushra Yasmin, (2017) "Production Efficiency analysis of Capsicum (Bell Pepper) Cropping System under the Tunnels in Punjap, Pakisthan. Paper presented at Southern Agricultural Economics Association $49^{\text {th }}$ Annual Meeting, Alabama.

Horticultural Statistics at a glance (2017), Ministry of Agriculture and Farmers welfare, Govt. of India.

Kumar, Praveen, Chauhan, R.S. and Grover, R. K., (2016) "Economic analysis of capsicum cultivation under Polyhouse and open field conditions in Haryana", International Journal of Farm Sciences. 6(1) 96-100.

Rai, N., Nath, A., Yadav, D.S. and Patel, K.K. 2004. Effect of polyhouse on shelf-life of bell pepper grown in Meghalaya. National Seminar on Diversification of Agriculture through Horticultural Crops, held at IARI Regional Station, Karnal, pp. S.P.22.

Sreedhara, D. S., Kerutagi, M. G., Basavaraja, H., Kunnal, L. B. and Dodamani, M. T., (2013) "Economics of capsicum production under protected conditions in Northern Karnataka", Karnataka Journal of Agricultural Sciences, 26 (2): 217-219.

Usman M, Ashfaq M and Ali I., (2013) "Economic analysis of statice cutflower production in Punjab, Pakistan", Pakistan Journal of Agriculture Sciences, 50(2): 311-315.

\section{How to cite this article:}

Senthilkumar S., K. R. Ashok, M. Chinnadurai and Sathyamoorthi K. 2018. Production Efficiency of Capsicum under Protected Cultivation in North West Region of Tamil Nadu, India. Int.J.Curr.Microbiol.App.Sci. 7(06): 2284-2291. doi: https://doi.org/10.20546/ijcmas.2018.706.273 